\title{
It's a long way to the other side of the table
}

\section{Elizabeth H. Stephens, MD, PhD}

When you're a medical student or a junior resident scrubbing with a chief resident on a given case, it can be very deceptive. There's music playing, the chief might be chatting about some football game last night, and whatever case it is, coronary bypass, mitral valve replacement, lobectomy, whatever, can seem to happen almost effortlessly. Even when the attending comes down and during crossclamp, there can be very little talk about the case itself. The case sort of flows along as if it has its own inertia, as if it is destined to go along a predefined path and the chief is an assistant nudging it slightly this way or that-and everything does go well. This gives the preconception that as the years go by and you progress to chief year, somehow you passively morph into a chief who can perform these cases effortlessly. And while it may appear that way, going through residency passively is like thinking that just by not falling asleep during advanced-placement calculus class you will do well on the advanced-placement examination. Furthermore, going through residency passively robs yourself of valuable learning and potential for success. Performing cardiothoracic surgery is not at all like a train going along tracks to a predetermined destination with the chief being the engineer making minor adjustments. Rather, once you're on the surgeon's side of the table perhaps a better analogy is carrying an injured patriot on your back through the jungle with booby traps right and left and no map, trying to navigate to base. While an almostinconsequential physical distance from the assistant's to surgeon's side, as Dr Craig Smith (cardiac surgeon and Chair of Surgery at Columbia) used to say, "It's a long way to the other side of the table." You then become the director of the operation, from pump management, to the surgical steps, to even anesthetic considerations. The level of detail that you need to know and direct during an operation is incredible and often may seem concealed until you're on the surgeon's side.

When first making that transition, my attendings told me to visualize the case the night before and morning of. They told me visualize every little detail, including the needle angles, pump management, and asking for specific items. I did

From the Department of Cardiovascular Surgery, Mayo Clinic, Rochester, Minn. Disclosures: Author has nothing to disclose with regard to commercial support.

Received for publication Nov 8, 2019; revisions received Nov 30, 2019; accepted for publication Dec 3, 2019; available ahead of print Feb 6, 2020.

Address for reprints: Elizabeth H. Stephens, MD, PhD, Department of Cardiovascular Surgery, Mayo Clinic, 200 First St, SW, Rochester, MN 55905 (E-mail: stephens. elizabeth@mayo.edu).

J Thorac Cardiovasc Surg 2020;159:2340-3

$0022-5223 / \$ 36.00$

Copyright (c) 2020 by The American Association for Thoracic Surgery

https://doi.org/10.1016/j.jtcvs.2019.12.077

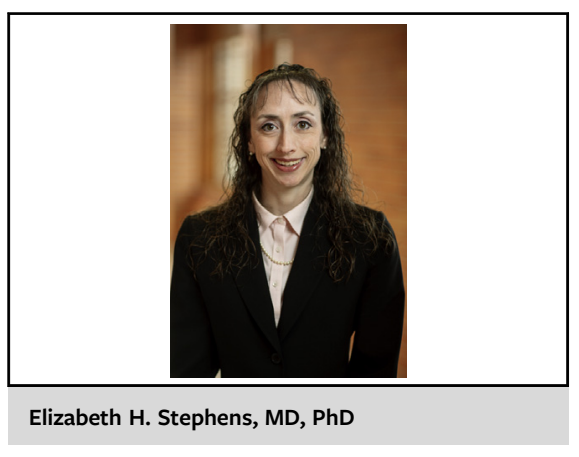

CENTRAL MESSAGE

Implementing deliberate practice in the midst of a busy training program can be challenging. This editorial provides perspective on how trainees can optimize their surgical training.

See Commentaries on pages 2343 and 2345 .

try that, but somehow my attention would wander. I discovered that I learned best by writing. This started out as a very junior resident writing down surgical steps and surgeon's preferences, but over time became more elaborate with diagrams showing angles, set-ups for anastomoses, and needle angles. This evolved into a book of "master" notes categorized by operation and surgeon-my "Bible" for residency (Figure 1). By the time I was heading over to the surgeon's side, taking a blank piece of paper and writing down the whole operation, including details such as needle angles and drawing diagrams of how things should be set up, became my way to prepare for each case. If writing, I wasn't veering off into space and my work could be checked relative to my "master" notes. Early on, this meant writing down absolutely everything. At first, I was actually ridiculed for my notes - one attending used to say to me, "Don't write this stuff down, this needs to be all in your head not on paper!" But after better understanding how I learn, my response became, "I need to keep writing this all down until it $i$ actually in my head." And by chief year he became so proud of my "black book" that he used to show it off to visiting professors and students, and insisted it should be published.

Not everyone needs or should have such a book, and maybe writing out the operation the night before from scratch isn't helpful for some (see Table 1 for potential 


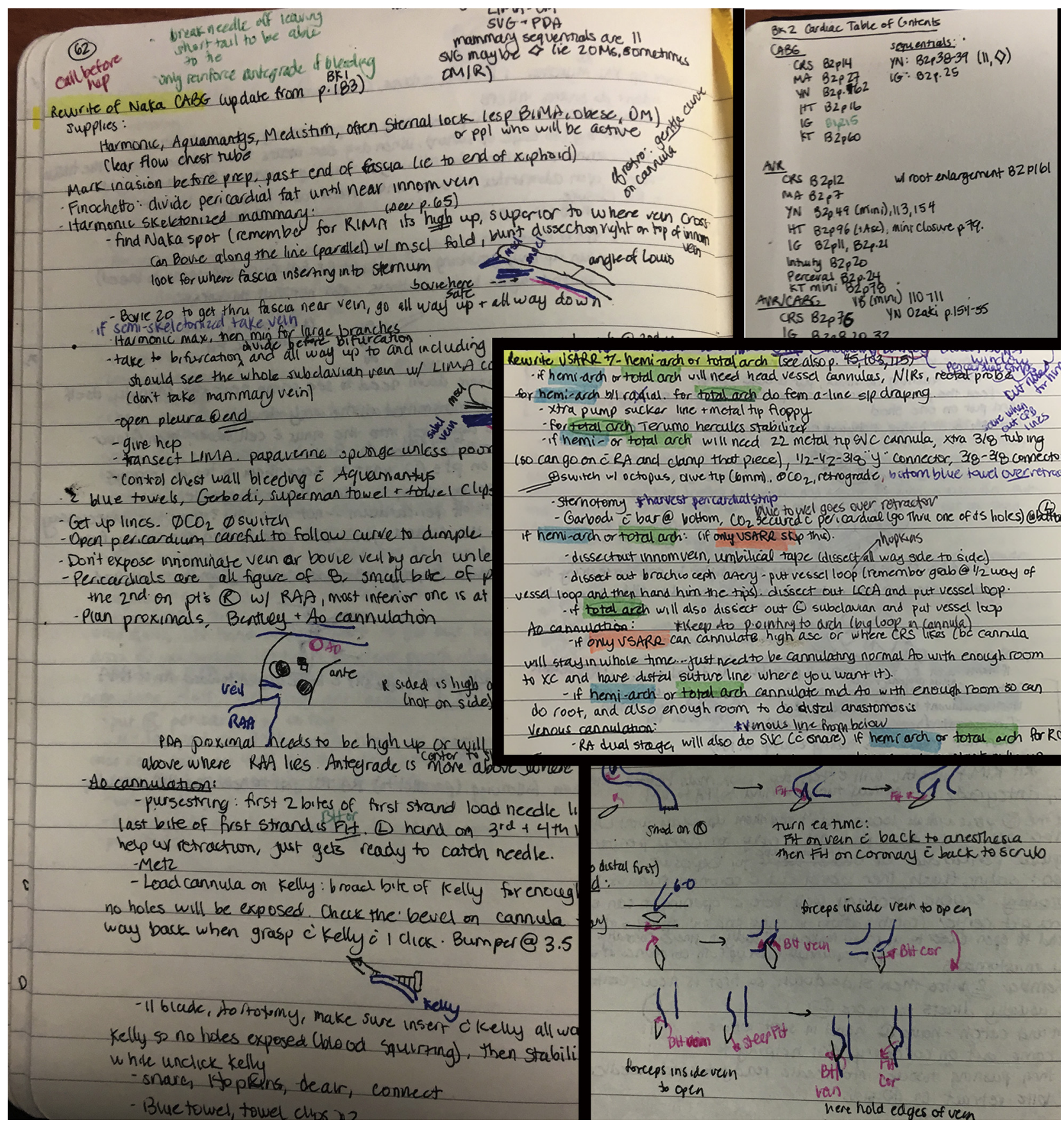

FIGURE 1. Example of a page from operative notebook with inset in upper right corner demonstrating table of contents with procedure stratified by attending, middle right inset demonstrates example of branching decision making during operation (how the operation changes for hemiarch vs total arch vs valve-sparing aortic root replacement), and lower right inset demonstrates an example of a diagram for a set-up of an operation (coronary anastomosis).

components), but the point is to figure out how best you learn and prepare for a case. Obviously, residents learn differently and pick things up at varying speeds, but you owe it to yourself and your patients to discover how you learn and optimize each case you scrub to maximize the learning potential. Much of residency you may spend feeling overwhelmed with work, but taking that extra time to figure out how you learn and can best prepare for cases, as well as learn from your cases, reaps bountiful rewards.

In my ex-life, I was a competitive gymnast. You watch these gymnasts on television and it looks so easy. But we would train 5 hours a day, doing tricks over and over and over again, with all the accompanying bumps and bruises, sore muscles and long nights, until the tricks did finally 
TABLE 1. Potential elements of an operative notebook

\begin{tabular}{|c|c|c|}
\hline Element & Examples & Role \\
\hline Key supplies & $\begin{array}{l}\text { Harmonic scalpel, special retractor, specific } \\
\text { sutures, or sizers }\end{array}$ & $\begin{array}{l}\text { Ensures elements readily available in the } \\
\text { operating room }\end{array}$ \\
\hline Preoperative planning & $\begin{array}{l}\text { Decision making for hemiarch vs total arch vs } \\
\text { valve-sparing aortic root replacement }\end{array}$ & Enables preoperative decision making \\
\hline Surgical steps & Timing of left ventricular vent placement & $\begin{array}{l}\text { Allows trainee to direct operation, ask ahead } \\
\text { for things to expedite the case }\end{array}$ \\
\hline \multicolumn{3}{|l|}{ Diagrams } \\
\hline $\begin{array}{l}\text { Anatomy } \\
\text { Sequence/direction of suture placemen }\end{array}$ & $\begin{array}{l}\text { Role of left hand retracting during coronary } \\
\text { anastomosis, anatomy to locate the } \\
\text { proximal portion of the internal mammary }\end{array}$ & $\begin{array}{l}\text { Efficiency of motion and steps, avoiding } \\
\text { complications }\end{array}$ \\
\hline Elements of emphasis & Ink color or highlighting & $\begin{array}{l}\text { When reviewing, reminds key elements } \\
\text { trainee doesn't want to forget }\end{array}$ \\
\hline Branching of operative decision-making & $\begin{array}{l}\text { In mitral valve disease, if valve repair vs } \\
\text { replacement }\end{array}$ & $\begin{array}{l}\text { Seamless transition between different } \\
\text { operations for a given underlying } \\
\text { pathology }\end{array}$ \\
\hline
\end{tabular}

become so smooth that they looked easy. For instance, before doing a front flip 4 feet off the ground on a 4-inch wide beam with a "blind landing" (can't see the beam coming until you land on it), we would do the same trick on a line marked on the floor, pretending that line was the balance beam, until we knew we were about to land in exactly the right spot. In the same way that many of us have learned about "deliberate practice" in sports, these principles should be applied to becoming a competent surgeon.

Deliberate practice has been well-studied in many fields and eloquently written about by Dearani and others as it portends to cardiac surgery. ${ }^{1-3}$ Simply stated, deliberate practice involves focused, deliberate tasks to improve performance with coaching and feedback. ${ }^{4}$ It has clearly been shown to be effective in cardiothoracic training. ${ }^{3}$ But what does deliberate practice look like when effectively applied in the context of a busy residency? How do these theoretical concepts hit the road, so to speak? These were questions with which I struggled. I knew what deliberate practice looked like in the setting of competitive gymnastics, but what does it practically look like in the setting of cardiothoracic surgery, particularly during residency with a pager constantly going off, the demands of my senior and junior residents, etc?

Simulation can be helpful, but many trainees have access to low-fidelity simulation that does not mimic the real tissues, the hole we work in, or the angles. Some programs have robust simulation curriculum, but frequently particularly high-volume clinical programs have limited structured simulation. Although most programs have quarterly wet labs or something equivalent in which experts "coach" trainees on specific skills, those experiences can have relatively little impact on the daily grind of figuring out how to successfully perform a given case. Some programs have simulation centers in which you can practice, and while helpful, that is likely the last place you want to go after a long call. And while accomplished athletes and musicians have frequent one-on-one coaching with feedback, for the resident this occurs in the setting of a case in the operating room; any practice or preparation outside of the operating room almost always is done independently. That said, intentional independent practice using a mock setup can be very helpful. Early on, simply the process of getting used to handling Castros, following the curve of the needle, etc, doesn't need fancy, realistic simulation setups. Later, creating a "hole" simulating the chest cavity and practicing needle angles for aortic or mitral valve replacement, for example, can be very helpful. Use whatever resources you have available to you to improve the areas that you have identified need work.

And even when the simulation may not feel very realistic, attendings notice. While practicing in my off hours for the Top Gun competition-which was a coronary anastomosis using a plastic vessel-two different attendings during cases that were completely different from bypass operations independently commented that I must have been practicing because my skills had substantially improved. I hadn't noticed any change, but it was clearly notable to them in a completely different surgical setting. Monitoring for progress when working on your own outside the operating room can be difficult. Unfortunately, this isn't like swimming or running where you can simply track your time to gage progress. Frequently there isn't any positive reinforcement or objective demonstration of improvement. Maybe it feels like the angles are coming more naturally in the operating room or you notice that next time you do the noncoronary 
sinus sutures for an aortic valve replacement you only loaded the needle once and nailed it.

During training, I also thought a lot about how to maximize the learning potential from each case. Before each case, I would write down what I wanted to do well or improve on. After each case, I would ask the attending for specific aspects that could be improved, and then I also wrote down items that I wanted to do better. Clearly, not all people learn by writing and visually seeing diagrams drawn out, or writing down things before and after each case, but being intentional about your training and trying to progress through and as a result of each case is key. Also, asking for feedback from your attending after each case on how you can improve shows your interest in becoming a better surgeon. This engages them, and sometimes you'll be surprised what they say-things you may never have noticed. You can also offer to dictate the case; this helps you review the specific steps of the case.

So why don't residents practice/prepare more or at least discuss it? Perhaps in part it appears uncool or weaklike those "closet gunners" in medical school who pretended that they didn't study. Those who practice or prepare, admit that they don't have it all down. Frankly, we are in training because we need to learn-if we knew how to do it already, we wouldn't be in training. Certainly, time during training is at an all-time premium, but this is also the key window to learn cardiothoracic surgery.

Deliberate practice and developing a method for how to prepare certainly doesn't end at the completion of training. All of us to excel must continually strive to improve, to not be satisfied with where we are, to visualize our destination and the road to get there. Whether this is fueled by a chip on their shoulder or just an insatiable internal drive, anyone who is great in their field continually works through this process. Obviously, there is no one answer or method, but a trainee who carefully considers what this process looks like for himself or herself will be greatly benefitted. This not only optimizes your progress as a trainee, but prepares you for your career ahead.

\section{References}

1. Dearani JA, Stulak JM. Commentary: In surgical training, practice makes....almost perfect. J Thorac Cardiovasc Surg. 2019;158:e15-6.

2. Dearani JA, Gold M, Leibovich BC, Ericsson KA, Khabbaz KR, Foley TA, et al. The role of imaging, deliberate practice, structure, and improvisation in approaching surgical perfection. J Thorac Cardiovasc Surg. 2017;154: 1329-36.

3. Han JJ, Patrick WL. See one-practice-do one-practice-teach one-practice: the importance of practicing outside of the operating room in surgical training. $J$ Thorac Cardiovasc Surg. 2019;157:671-7.

4. Ericsson KA. Deliberate practice and the acquisition and maintenance of exper performance in medicine and related domains. Acad Med. 2004;79:S70-81.
See Editorial page 2340 .

\section{Commentary: "If you can meet with triumph and disaster and treat those two impostors just the same"}

\author{
George L. Hicks, Jr, MD
}

\section{If you can meet with triumph and disaster and treat those two impostors just the same.}

$$
\text { —Rudyard Kipling }
$$

\footnotetext{
From the University of Rochester Medical Center, Rochester NY.

Disclosures: Author has nothing to disclose with regard to commercial support.

Received for publication Dec 9, 2019; revisions received Dec 9, 2019; accepted for publication Dec 10, 2019; available ahead of print Jan 29, 2020.

Address for reprints: George L. Hicks, Jr, MD, University of Rochester Medical Center, 401 Elmwood Ave, Rochester, NY 14642 (E-mail: george_hicks@urmc. rochester.edu).

J Thorac Cardiovasc Surg 2020;159:2343-4

$0022-5223 / \$ 36.00$

Copyright (c) 2020 by The American Association for Thoracic Surgery

https://doi.org/10.1016/j.jtcvs.2019.12.044
}

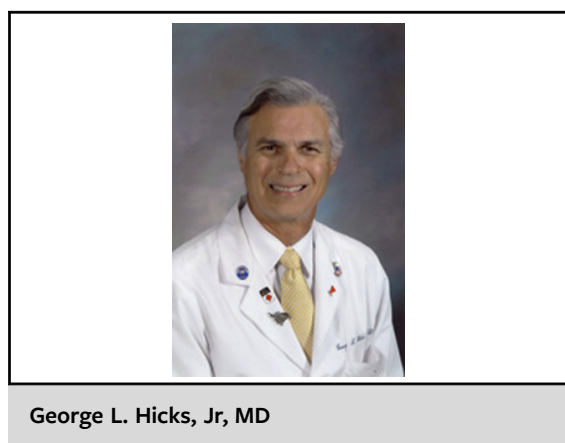

CENTRAL MESSAGE

One person's advice about succeeding in a surgical residency.

The unforgettable lines of the immortal Rudyard Kipling poem "If" remind us that life is a battle, a constant struggle to achieve perfection such that in the end "you 